\title{
PEMBERDAYAAN MASYARAKAT PEMERHATI ANGGREK MELALUI PELATIHAN PENGENALAN JENIS DAN BUDIDAYA ANGGREK DI KAMPUNG KWAU DISTRIK WARMARE KABUPATEN MANOKWARI
}

\section{Community Empowerment Efforts for Orchid Enthusiasts Through Species Introduction and Cultivation Training in Kwau Village, Warmare District, Manokwari Regency}

\author{
Agustina Yohana Setyarini Arobaya ${ }^{1,2)^{*}}$, Bernadetta Margaretha Gunarsih Sadsoeitoeboen ${ }^{1)}$, \\ Cicilia Maria Erna Susanti ${ }^{3)}$, Dina Arung Padang ${ }^{4)}$, Endra Gunawan ${ }^{3)}$, Francina Frenshegty \\ Kesaulija $^{4)}$, Kukuh Saptoyudo ${ }^{5)}$, Susanti Tasik ${ }^{6)}$, Samuel Mandacan ${ }^{7)}$ \\ ${ }^{1)}$ Laboratorium Konservasi dan Lingkungan Hidup, Fakultas Kehutanan, Universitas Papua, Jl. \\ ${ }^{2)}$ Pusat Penelitian Keanekaragaman Hayati, Universitas Papua; \\ ${ }^{3}$ Laboratorium Teknologi Hasil Hutan, Fakultas Kehutanan, Universitas Papua; \\ ${ }^{4}$ Laboratorium Perencanaan dan Menejemen Hutan, Fakultas Kehutanan, Universitas Papua; \\ ${ }^{5}$ Laboratorium Sylvikultur, Fakultas Kehutanan, Universitas Papua \\ Gunung Salju, Amban, Manokwari, Papua Barat 98314; \\ ${ }^{5}$ Dinas Pertanian, Peternakan dan Perkebunan Kabupaten Manokwari, Papua Barat \\ ${ }^{7}$ Tokoh Masyarakat Adat Kampung Kwau, Disrtik Warmare, Kabupaten Manokwari.
}

Article history

Received: Mar 06, 2021;

Accepted: Aug 17, 2021

* Corresponding author:

E-mail:

agustinaarobaya@yahoo.co

m, a.arobaya@unipa.ac.id

DOI: https://doi.org/10.465

49/igkojei.v2i3.196

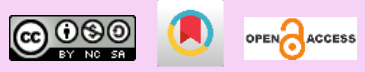

\begin{abstract}
Orchids are known as exotic plants that not only have many potentials but are also able to show off the national glamor, these plants are in great demand by ornamental plant enthusiasts. The beauty and durability of the flowers are the main reasons for these orchids to be hunted and traded either locally, nationally, or even internationally. Efforts to conserve natural orchid species with both ecologic and economic value should be initiated immediately to protect the endemic and rare species. One of the efforts made is through counseling activities and training on the topic of introduction of the species and the cultivation of orchids to people who have access to these biological resources and utilize them as a source of income to fulfill their daily needs. This activity was held for one week in Kwau Village, Warmare District, Manokwari Regency. The approach taken in this activity was counseling by providing material and hands-on field practice. Three orchid farmer groups were listed as training participants who received greenhouse and orchid plant facilities as grants from the regency's agriculture government agency (Dinas Pertanian, Peternakan dan Perkebunan Kabupaten Manokwari). The practice of introducing the species and pollination methods of the plants was carried out directly on flowering orchids within the greenhouses and also at the local community's gardens. Active participation was shown not only by the participants in the group but also by the entire Kwau village community.
\end{abstract}

Keywords: Orchid; Orchid-Enthusiast; Papua; Sylvi-Culture

\section{ABSTRAK}

Anggrek dikenal sebagai tumbuhan eksotik memiliki daya guna dan pesona nusantara yang banyak diminati oleh penggemar tanaman hias. Kemolekan dan daya tahan Bunganya menjadi pemicu sehingga anggrek ini sering di buru dan diperdagangakan baik lokal, nasional maupun internasional. Upaya pelestarian jenis anggrek alam yang memiliki nilai ekologis dan ekonomis perlu segera mungkin diinisiasi dalam rangka perlindungan jenis tumbuhan endemic dan tergolong langka. Salah satu upaya yang dilakukan adalah melalui kegiatan 
penyuluhan dan pelatihan pengenalan jenis dan budidaya anggrek kepada masyarakat yang memiliki sumberdaya hayati tersebut dan menggunakannya sebagai sumber income untuk pemenuhan kebutuhan hidup sehari-hari. Kegiatan ini dilaksanakan selama satu minggu di Kampung Kwau, Distrik Warmare, Kabupaten Manokwari. Pendekatan yang dilakukan dalam kegiatan ini adalah penyuluhan dengan pembekalan materi dan praktek langsung di lapangan. Tiga kelompok tani anggrek tercatat sebagai peserta pelatihan yang menerima bantuan fasilitas green house dan tanaman anggrek dari Dinas Pertanian, Peternakan dan Perkebunan Kabupaten Manokwari. Praktek pengenalan jenis dan pernyerbukan tanaman dilakukan langsung pada tanaman anggrek yang berbunga di dalam green house dan dipekarangan rumah masyarakat. Partisipasi aktif diperlihatkan bukan hanya oleh peserta dalam kelompok tetapi di ikuti oleh seluruh masyarakat kampung Kwau.

Kata Kunci: Anggrek; Budidaya; Papua; Pemerhati anggrek.

\section{PENDAHULUAN}

Tumbuhan anggrek sudah menjadi puspa pesona bukan hanya di nusantara tetapi juga di seluruh dunia. Keunikan bunga anggrek menjadi pemicu bagi pemerhati anggrek untuk memburu, mengoleksi dan menyilangkan beranekaragam bunga yang diperoleh untuk mendapatkan hasil perbungaan yang unik dan tahan lama. Potensi anggrek ini juga mendorong pemerhati anggrek untuk mengembangkannya menjadi tanaman hias yang cukup menjanjikan dan memiliki nilai ekonomi yang dapat mendatangkan income bagi pemiliknya.

Kebanyakan pemerhati anggrek yang sekaligus menjadi pengguna memiliki pengetahuan yang terbatas akan nama jenis. Sehingga terkadang sering terjadi kekeliruan dalam penamaan jenis anggrek yang diperjualbelikan. Apabila anggrek tersebut digunakan dalam program penyilangan akan terjadi kesimpangsiuran dalam menentukan asal nama tetua dari jenis yang disilangkan. Selain itu juga sering terjadi keterbatasan dalam hal bagaimana mengembangkannya guna menjaga ketersediaan stok tanaman yang diminati untuk diperdagangkan kepada pengguna. Oleh karena itu untuk mencegah perambahan secara terus menerus dari alam program budidaya yang baik dan benar perlu diketahui oleh para petani dan pemerhati anggrek.

Pelatihan ini dimaksudkan untuk membekali peserta dengan pengetahuan tentang pengenalan jenis anggrek alam Papua dan melakukan praktek secara langsung dalam melakukan budidaya di penangkaran anggrek yang dimiliki oleh kelompok petani anggrek dengan menggunakan bahanbahan tanaman yang sudah ada di penangkaran baik tumbuhan anggrek yang dikumpulkan dari hutan di sekitarnya ataupun yang diperoleh dari sumber lainnya. Hasil dari pelatihan ini diharapkan peserta dapat memperoleh pengetahuan dan ketrampilan dalam mengembangkan koleksinya dengan teknik penamaan yang benar dan budidaya anggrek secara vegetatif dan generatif. Lebih jauh diharapkan agar peserta juga lebih mengenal dan melindungi jenis anggrek endemik yang sudah mulai susah dijumpai dalam hutan bahkan terancam keberadaannya sebagai salah satu upaya konservasi eksitu anggrek alam Papua. 


\section{METODE}

Persiapan dan sosialisasi kegiatan pelatihan dilakukan di Laboratorium Konservasi dan Lingkungan Hidup Fakultas Kehutanan Universitas Papua dan Balai Pertemuan Kampung Kwau (Gambar 1).

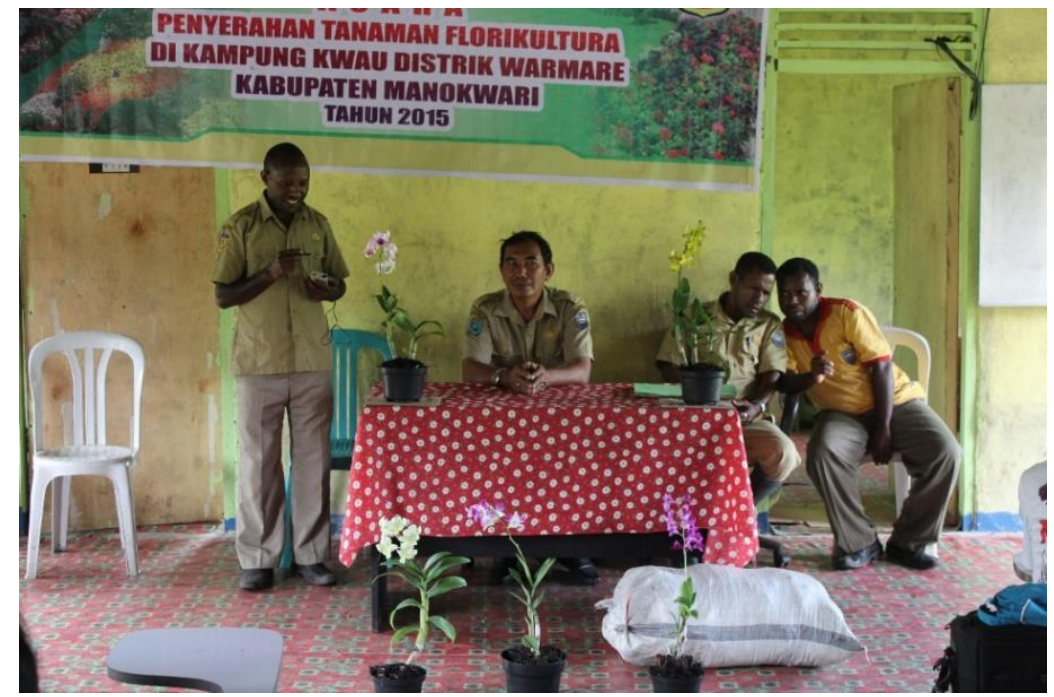

Gambar 1. Sosialisasi kepada masyarakat dan dihadiri para tokoh, aparat kampung Kwau serta stakeholder

Pada tahapan ini kami juga kami melakukan pendekatan kepada tiga kelompok tani anggrek yang menjadi binaan Dinas Pertanian, Peternakan dan Perkebunan Kabupaten Manokwari di Kampung Kwau. Selain penyiapan materi pelatihan dan cara penyampaiannya serta praktek, peralatan lapangan juga disiapkan mengingat kondisi kampung Kwau yang berada jauh dari sarana listrik.

Kegiatan pelatihan dilaksanakan di Kampung Kwau Disktrik Warmare Kabupaten Manokwari, Papua Barat dalam beberapa tahap selama sebulan antara lain dengan melakukan persiapan sebelum ke lapangan. Komunikasi juga dilakukan dengan pihak Dinas Pertanian, Peternakan dan Perkebunan Kabupaten Manokwari yang menjadi fasilitator dalam kegiatan tersebut sekaligus pembina petani anggrek setempat. Dinas Pertanian, Peternakan dan Perkebunan Kabupaten Manokwari membantu transportasi ke lokasi berlangsungnya kegiatan (Gambar 2).

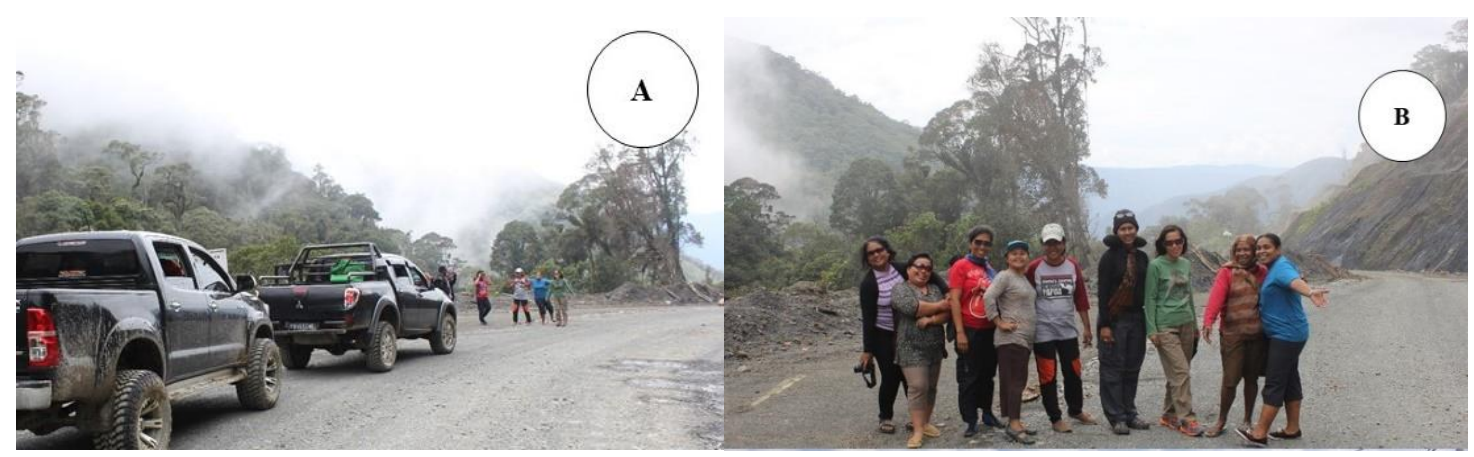

Gambar 2 (A). Perjalanan ke lokasi dengan moda transportasi darat; (B). Tim Fahutan dalam perjalanan ke lokasi kegiatan. 
Dalam pelaksanaan kegiatan penulis mendapat bantuan material dan prasarana transportasi oleh kepala dinas dan beberapa staf dari Dinas Pertanian, Peternakan dan Perkebunan Kabupaten Manokwari yang sekaligus menjadi motivator dan fasilitator pendamping masyarakat di Kampung Kwau selama di lapangan.

Peserta yang dilatih dalam kegiatan ini terdiri dari tiga kelompok yang masing-masing kelompok memiliki greenhouse koleksi anggrek. Fasilitas greenhouse dan tanaman anggreknya merupakan bantuan yang diberikan oleh Dinas Pertanian, Peternakan dan Perkebunan Kabupaten Manokwari dalam rangka menunjang dan membangun ekonomi kreatif masyarakat terutama bagi ibu-ibu di kampung Kwau.

Emat tahapan dalam pelaksanaan kegiatan pelatihan pengenalan jenis dan teknik budidaya anggrek yaitu:

1. Penyerahan material tumbuhan untuk bahan pelatihan oleh kepala Dinas Pertanian, Peternakan dan Perkebunan Kabupaten Manokwari dan Tim Fahutan UNIPA kepada peserta pelatihan (Gambar 3).

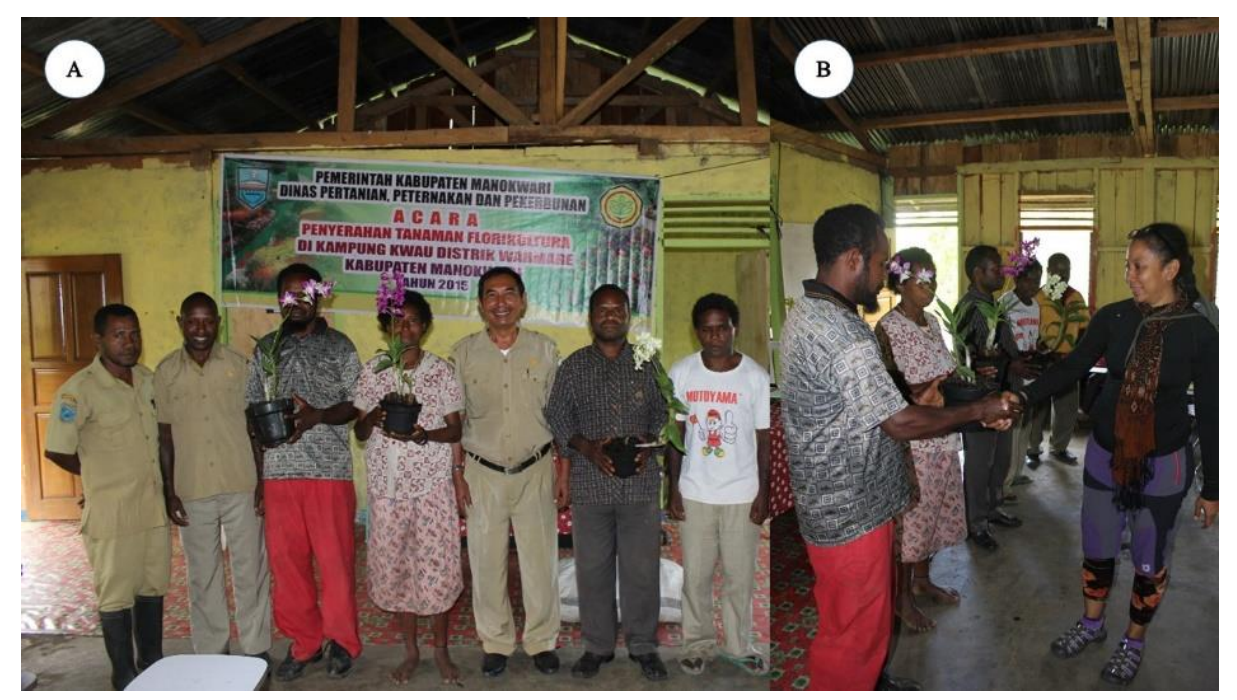

Gambar 3. (A). Penyerahan material tumbuhan anggrek oleh Kepala Dinas Pertanian, Peternakan dan Perkebunan Kabupaten Manokwari, (B). Tim UNIPA kepada peserta pelatihan

2. Pembekalan materi pelatihan mengenai pengenalan jenis disampaikan secara langsung kepada peserta (Gambar 4). Materi pengenalan jenis terdiri dari 1) pengertian mengenai tumbuhan anggrek, 2) bagian-bagian tumbuhan anggrek, 3) keanekaragaman jenis anggrek alam Papua, 4) penyebaran jenis anggrek, 5) tipe habitat tempat tumbuh, 6) bagaimana anggrek bisa tumbuh dan memperbanyak diri secara alami. Materi ini disampai dengan menggunakan gambar dan bahasa yang sederhana seperti menggunakan nama lokal yang banyak dikenal dan dipadupadankan dengan nama ilmiah jenis anggreknya. Verifikasi jenis selama pelatihan juga dilakukan dengan menggunakan buku-buku dan jurnal yang memuat informasi mengenai anggrek alam Papua (Schuiteman 2013, O'Byrne 1994, Cribb 1986). 


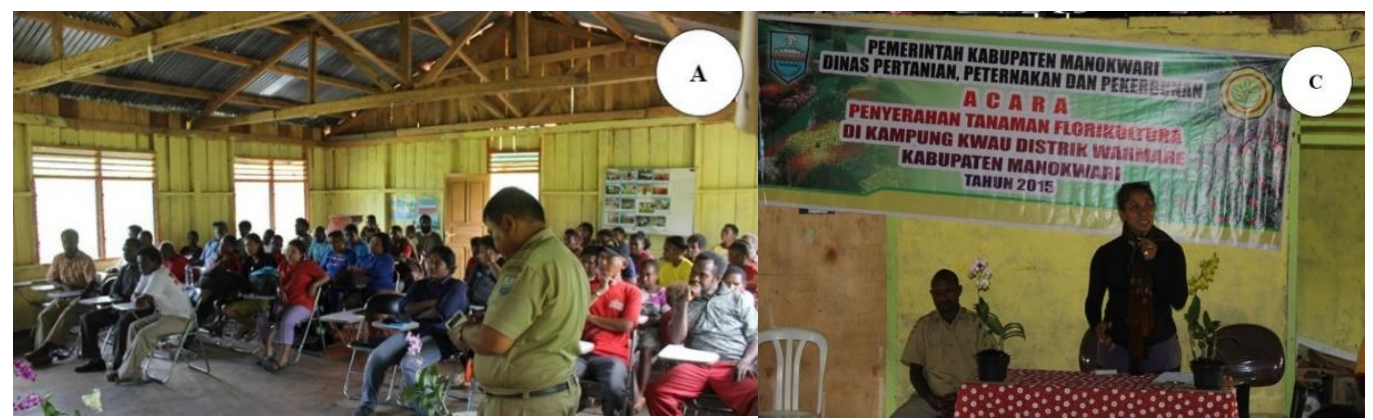

Gambar 4 (A). Staf instansi Dinas Pertanian sedang memberikan arahan untuk pembagian kelompok kepada para peserta, (C). Penyampaian materi oleh Tim Fahutan

3. Kegiatan praktek pengenalan jenis dengan meninjau setiap koleksi anggrek di screen house masing-masing kelompok. Dilakukan juga praktek tata cara penyilangan secara buatan dari bunga yang sedang mekar. Praktek penyilangan ini dilakukan dengan menggunakan tusuk gigi untuk memindahkan komponen bunga yaitu polen yang tersimpan dalam kantong polen ke bunga yang sama atau ke bunga lain dalam satu tangkai perbungaan atau rumpun bunga sejenis lainnya.

4. Kegiatan praktek pemeliharaan anggrek melalui pemupukan dengan menggunakan sumberdaya yang tersedia seperti menggunakan air bekas cucian beras sebagai pupuk organik. Dapat juga menggunakan air cucian ikan atau daging yang dicampurkan ke dalam air cucian beras dan didiamkan dua sampai tiga hari lalu disemprotkan seminggu sekali ke tanaman sebagai bahan pupuk organik yang murah dan efisien. Hal lain terkait pemeliharaan adalah masyarakat juga terinfokan pada saat pelatihan berlangsung tentang bagaimana menyiangi bagian tanaman yang sudah kering dan mati atau jika ada hama yang menggangu dan menyerang tanaman yang dipelihara.

\section{HASIL DAN PEMBAHASAN}

Semua anggota tim terlibat menjadi pendamping pada saat kegiatan pelatihan, dilakukan kepada setiap kelompok tani anggrek karena lokasi screen house agak berjauhan sehingga semua anggota kelompok memiliki bekal pengetahuan yang sama. Peserta terdiri dari kelompok ibu, bapak dan pemuda yang mewakili ketiga kelompok anggrek binaan.

Setelah peserta menerima pembekalan materi pengenalan jenis dan bagaimana cara budidaya anggrek, maka kepada peserta diberikan kesempatan untuk melakukan praktek untuk melihat sejauh mana peserta menyerap materi dan mengenal anggrek yang dikumpulkan dari hutan dan dilekatkan pada pohon atau pagar pekarangan dan dikoleksi dalam screen house (Gambar 5). 


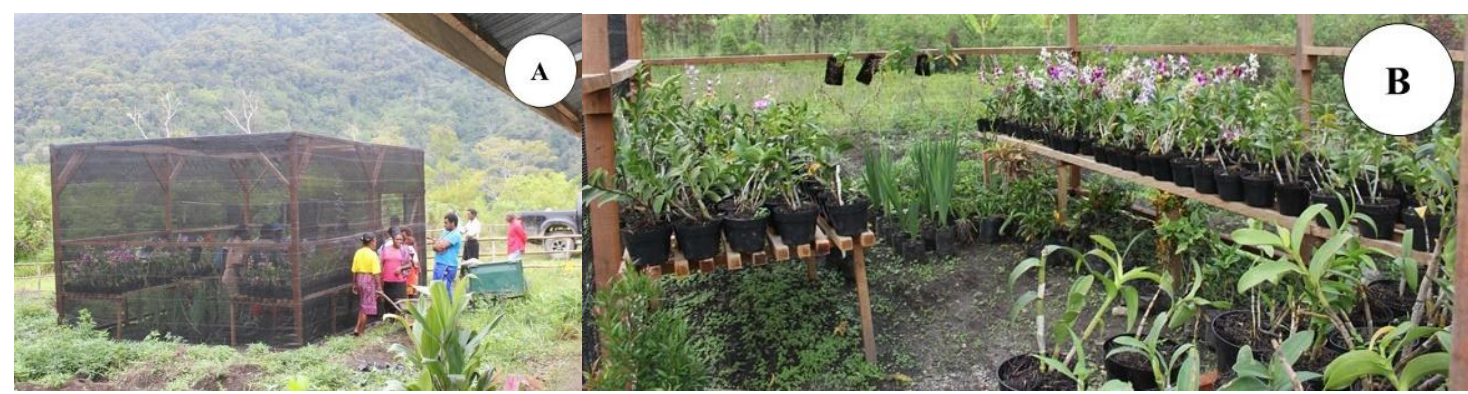

Gambar 5 (A). Screen house kelompok tani anggrek di Kampung Kwau; (B). Koleksi jenis anggrek dari marga Dendrobium

Peserta juga dibekali dengan praktek mengenai budidaya juga dilakukan dengan pendekatan generatif dan vegetatif. Pada saat praktek mengenai budidaya dengan pendekatan generatif, diajarkan tentang teknik menyerbukan bunga secara buatan. Bilamana proses penyerbukan buatan berhasil akan terjadi pembuahan dan dalam beberapa minggu ke depan akan terbentuk bakal buah pada bagian bawah bunga yaitu bagian ovarium yang mulai membesar dan berkembang menjadi buah dalam 6 sampai 8 minggu.

Pengenalan budidaya anggrek sangat bermanfaat karena program budidaya tanaman anggrek dapat menciptakan suasana asri dan ikut melestarikan lingkungan sekitar. Disamping dapat menikmati keindahan bunganya, membudidayakan anggrek juga mampu menciptakan peluang usaha, karena harga jual tanaman anggrek ataupun bunga anggrek sebagai bunga potong cukup tinggi dan permintaannya cukup tinggi. Oleh karena itu pelatihan seperti ini juga dilakukan di daerah lain di Indonesia (Pharmawati et al., 2020).

Peserta menunjukkan antusiasme yang cukup baik ketika praktek penyerbukan bunga dilakukan (Gambar 6). Secara bergantian mereka mencoba untuk membuka kap kantong polen, kemudian mengambil kantong berisi polen dengan sangat berhati-hati dan memindahkannya ke bagian bunga yang berbentuk huruf $\mathrm{V}$.

Pada bagian ini biasanya terdapat nektar yang menjadi daya tarik bagi penyerbuk alami seperti lalat buah atau lebah kecil yang berkunjung dan mengambil nektar dari bunga. Nektar juga berfungsi sebagai perekat bilamana polen jatuh atau diletakkan pada bagian tersebut. Bilamana terjadi pelekatan pada bagian tersebut kemungkinan besar terjadi keberhasilan penyerbukan yang menghasilkan bakal buah.

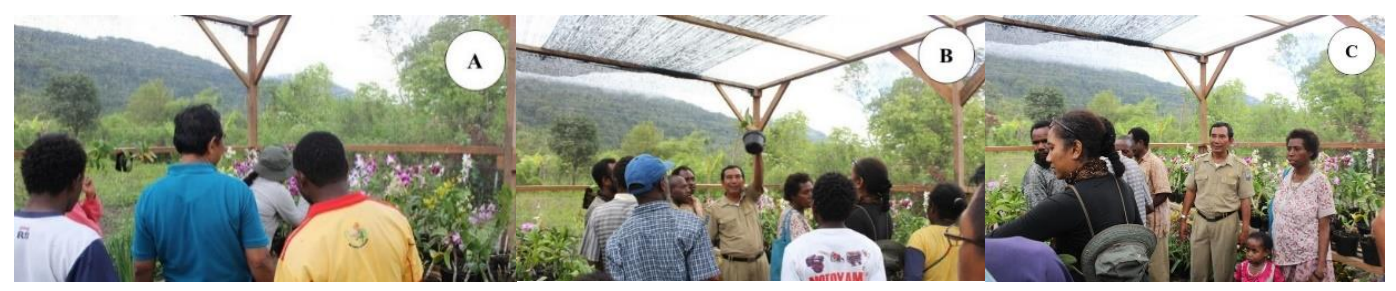

Gambar 6 (A). Praktek penyerbukan secara buatan yang dilakukan peserta kelompok 1; (B). Peserta kelompok 2; (C). Pengenalan jenis angrek di kelompok 3 di screen house masing-masing kelompok 
Ketika buah sudah mulai menunjukkan perubahan warna dari hijau ke kuning menunjukkan kematangan buah yang siap untuk di semaikan baik secara alami atau buatan (Gambar 7). Buah yang telah menguning dapat digolongkan sebagai buah yang sudah matang dan siap untuk disebarkan secara alamiah pada media pakis atau sabut kelapa, tetapi juga dapat disebarkan oleh angin dan air secara alami. Ketika terjadi penyerbukkan dan terbentuk buah dipenangkaran anggrek petani, maka proses penyebaran terjadi langsung di tempat tersebut.

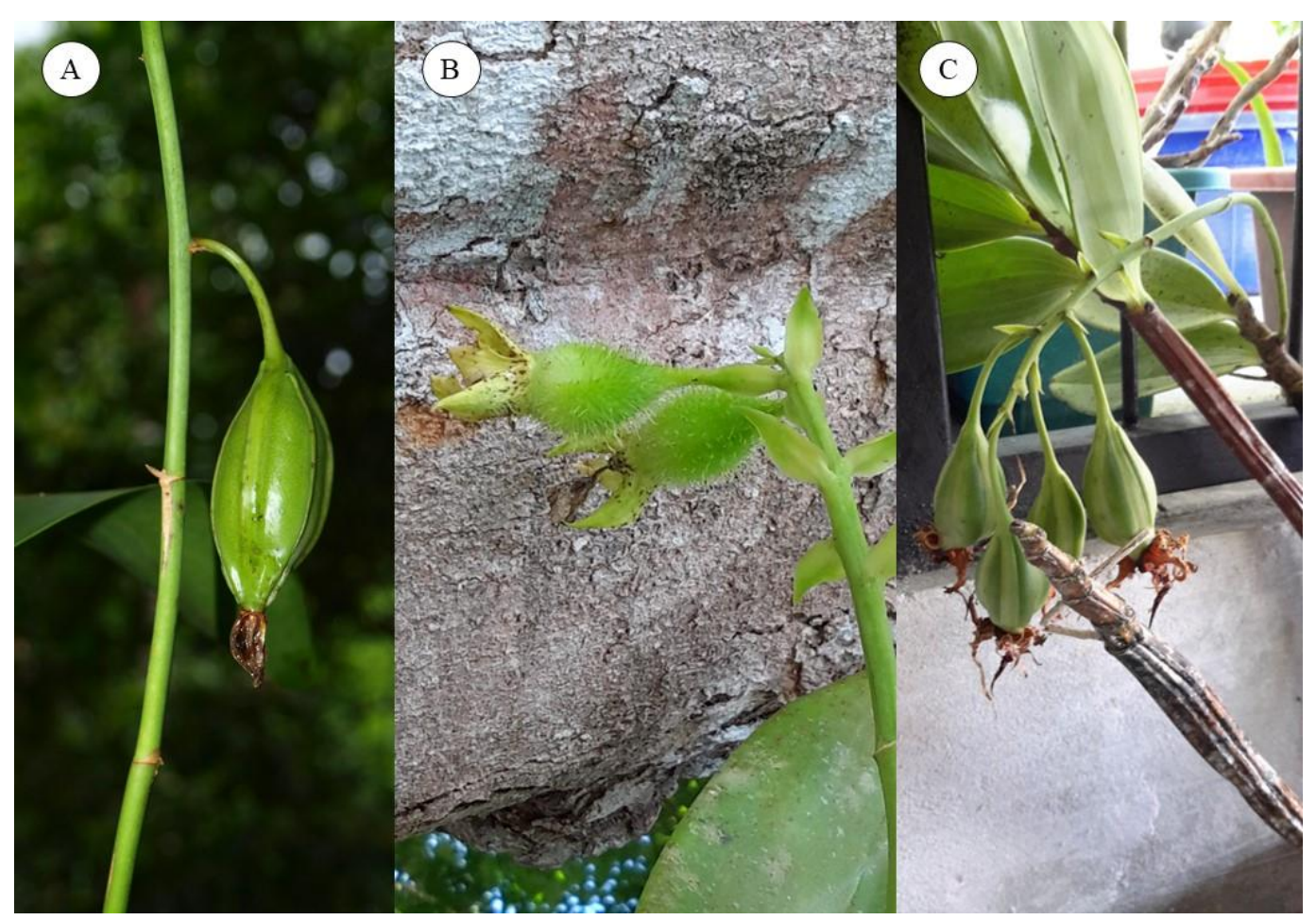

Gambar 7 (A). Buah hasil persilangan anggrek secara alami pada jenis Grammatophyllum scriptum; (B) Hasil persilangan buatan pada jenis Dendrobium macrophyllum dan (C) Dendrobium spectabile

Tahap selanjutnya adalah mendampingi masyarakat dalam melakukan upaya budidaya dari biji yang membutuhkan waktu yang cukup lama sehingga giat tersebut dapat menjadi pembelajaran berguna bagi masyarakat bahwa anggrek juga membutuhkan waktu untuk dapat bertumbuh dengan suasana lingkungan yang mendukung seperti suhu, kelembaban, cahaya dan air.

Keempat aspek lingkungan tersebut merupakan penunjang utama dalam keberhasilan regenerasi anggrek baik di alam maupun di penangkaran. Keempat aspek tersebut selama ini kurang mendapat perhatian dari para pemerhati anggrek yang mengoleksi dan mengumpulkan serta memelihara anggrek. Kondisi iklim mikro di kampung Kwau cukup mendukung keberhasilan pelestarian anggrek karena ketersediaan aspek kelembaban, suhu, air dan intesitas cahaya yang cukup memadai bilamana terjadi perubahan iklim yang cukup ekstrim.

Para peserta sangat antusias dalam melakukan kegiatan pelatihan, nyata dalam keaktifan mereka bertanya serta melatih pengetahuan mereka tentang mengidentifikasi jenis anggrek yang ada di sekitar 
kampung melalui pendekatan karakter anggrek. Dalam kegiatan budidaya, perserta juga diperkenalkan dengan media tanam yang ada di sekitar mereka, serta teknik penyerbukan yang selama ini belum begitu diketahui dengan baik. Pengetahuan petani tentang pengaruh faktor lingkungan sudah cukup baik, dilihat dari penempatan jenis anggrek yang disesuaikan dengan kondisi tempat tumbuh seperti ada yang memerlukan naungan, ada yang di tempat terbuka, serta kebutuhan pohon inang sebagai tempat tumbuh.

Keberhasilan program pelatihan dan penyuluhan ini perlu ditindaklanjuti dengan kegiatan monitoring dan evaluasi sampai masyarakat bisa mandiri dan mampu mengelola sumberdaya hayati dari hasil hutan non kayu. Monitoring terus dilaksanakan oleh pihak Dinas Pertanian, Peternakan dan Perkebunan Kabupaten Manokwari dan bekerjasama dengan pihak Fakultas Kehutanan Universitas Papua (Gambar 8).

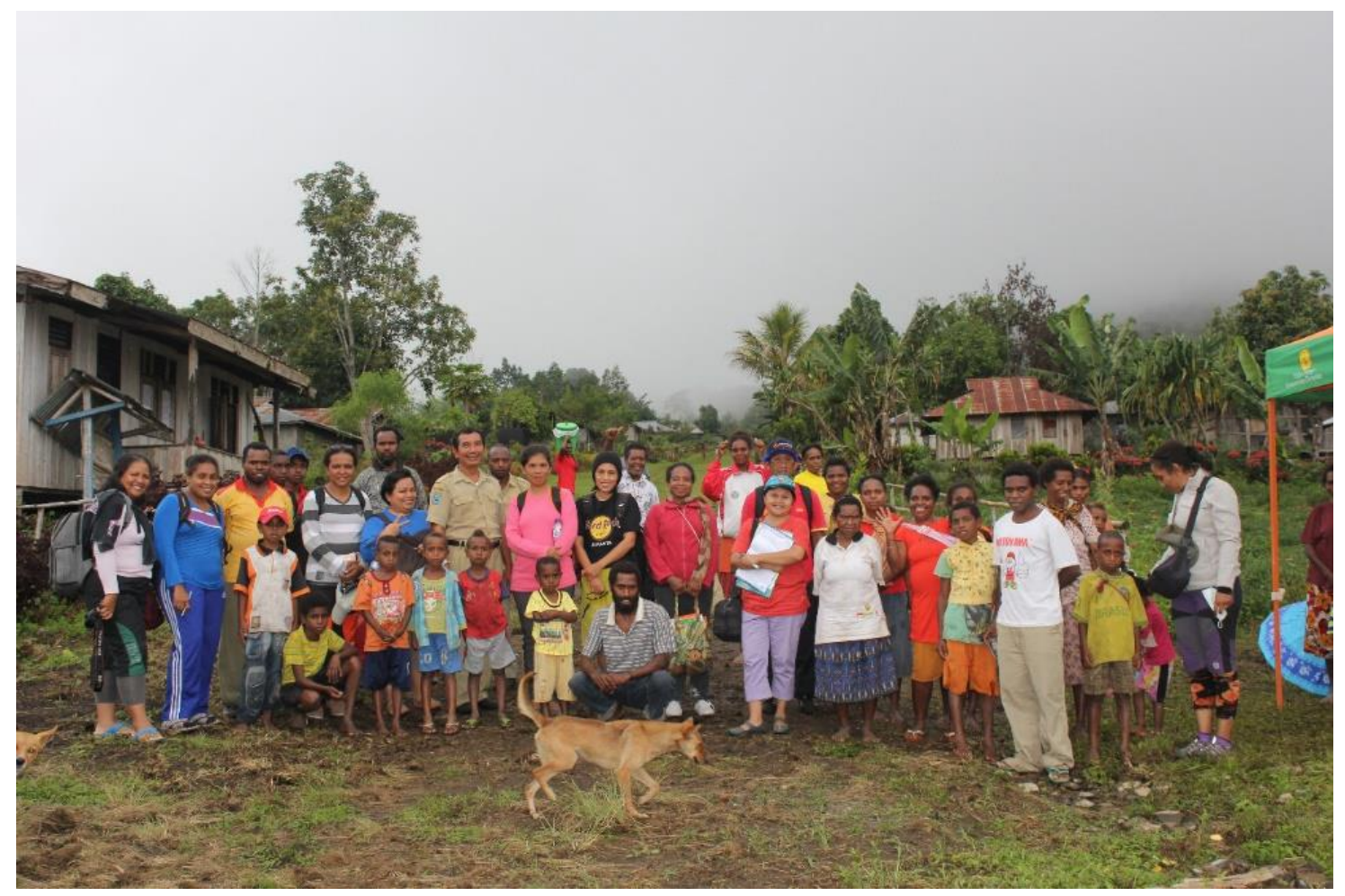

Gambar 8. Tim Dinas Pertanian, Peternakan dan Perkebunan Kabupaten Manokwari bersama masyarakat kampung Kwau dan Tim Fahutan Unipa.

\section{KESIMPULAN}

Peserta mulai mengetahui jenis anggrek yang dikumpulkan dan dikoleksi dalam greenhouse masing-masing kelompok. Pengetahuan peserta bertambah dengan belajar mempraktekkan bagaimana menyerbukan bunga dalan proses budidaya secara buatan. Antusiasme peserta untuk menjaga anggrek alam yang dimiliki cukup tinggi dengan memperhatikan dan mempraktekan proses budidaya yang diajarkan.

Perlu pendampingan berkelanjutan kepada petani anggrek agar proses pengenalan jenis dan budidaya ini bisa berlanjut sampai ke tahap pemasaran produk hasil silangan buatan petani sehingga 
mengurangi proses perambahan dan perburuan anggrek yang sudah mulai langka. Perbaikan sarana dan prasarana angkutan agar kelompok tani ini selain dapat membawa hasil pertaniannya untuk dijual ke kota, juga dapat menarik pengunjung berwisata ekologi ke kampung Kwau yang memiliki fasilitas ekowisata dan penginapan yang cukup memadai.

\section{UCAPAN TERIMA KASIH}

Penulis ucapan terima kasih kepada 1) Kepala Dinas Pertanian, Peternakan dan Perkebunan Kabupaten Manokwari beserta staf yang memberikan bantuan material, moril dan transportasi sehingga penulis boleh berada di lapangan dan kegiatan pelatihan dapat dilaksanakan, 2) teman dosen dan mahasiswa Fakultas Kehutanan yang memberi dukungan kepada kami selama persiapan hingga kegiatan berlangsung di lapangan, 3) Kepala Kampung Kwau yang memberikan ijin sehingga kegiatan ini dapat terlaksana dengan baik dan masyarakat yang berpartisipasi secara aktif dalam kegiatan.

\section{DAFTAR PUSTAKA}

Cribb, PJ. (1986). A revision of Dendrobium sect. Spatulata (Orchidaceae). Kew Bulletin, 41(3), 615692. Retrieved from www.jstor.org/stable/4103119

O'Byrne, P. (1994). Lowland Orchid of Papua New Guinea. Singapore: Singapore Botanic Gardens. Pharmawati, M. Wrasiati, L.P., Wijaya, Sutrisna, I.M.A., Defiani, M.R. (2020). Pelatihan budidaya dan rintisa usaha anggrek bagi pemuda desa di Budaga Kabupaten Klungkung Bali. Buletin Udayana Mengabdi Vol. 19(2): 235-240

Schuiteman, A. (2013). A guide to Dendrobium of New Guinea. Kinabalu, Sabah, Malaysia: Natural History Publications. 